\title{
The Role of Value Deliberation to Improve Stakeholder Participation in Issues of Water Governance
}

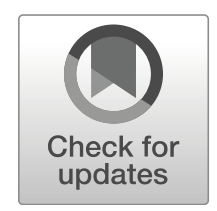

\author{
Klara Pigmans $^{1} \cdot$ Huib Aldewereld ${ }^{2} \cdot$ Virginia Dignum $^{1} \cdot$ Neelke Doorn $^{1}$
}

Received: 21 December 2017 / Accepted: 24 June 2019 /

Published online: 3 October 2019

(C) The Author(s) 2019

\begin{abstract}
Stakeholder participation is a requirement for environmental decision-making in the European Union. Despite this, numerous instances can be seen in water governance in which stakeholders feel undervalued and unheard, thereby creating unfavourable procedural outcomes, resistance and conflict. In this article, we propose that a process of early-stage deliberation constructed around the values of the stakeholders involved can reduce, and even prevent such conflicts. We suggest that if values that stakeholders perceive as relevant can be identified and discussed as part of the deliberation process then (1) stakeholder preferences can change, and (2) participants can develop a mutual understanding of each other's values and perspectives. To explore these propositions, facilitated workshops were conducted at two Dutch water institutes, based around the topics of land subsidence and the pharmaceutical contamination of water systems. Participants deliberated on values that they considered relevant. The results suggest that mutual understanding of stakeholders' perspectives increases as a result of value-based deliberation.
\end{abstract}

Keywords Values - Deliberation - Stakeholder participation · Water governance · Mutual understanding

Klara Pigmans

k.a.m.pigmans@tudelft.nl

Huib Aldewereld

huib.aldewereld@hu.nl

Virginia Dignum

m.v.dignum@tudelft.nl

Neelke Doorn

n.doorn@tudelft.nl

1 Department of Technology, Policy, and Management, Delft University of Technology, Jaffalaan 5, Delft 2628BX, The Netherlands

2 Institute for ICT, University of Applied Sciences Utrecht, Utrecht, The Netherlands 


\section{Introduction}

Stakeholder participation is widely recognised as a central component of environmental decision-making. This is reflected in the Aarhus Convention ${ }^{1}$ and subsequent environmental legislation, with both the European Water Framework Directive (Directive 2000/60/DC) and the European Floods Directive (Directive 2007/60/EC) placing similarly strong emphasis on the role of the stakeholder in the water management process. In its most general sense, stakeholder participation refers to a process that facilitates the inclusion of those involved in, affected by, knowledgeable of, or having expertise or experience relevant to the issues at stake (Van Asselt and Rijkens-Klomp 2002). This process can range from simple information provision to independent, public-led decision-making (Mostert 2003). Benefits commonly associated with stakeholder participation include better use of the available knowledge and experiences of different stakeholders; increased public acceptance, through more transparent decision-making processes; and reduced litigation, delays, and inefficiencies in outcome implementation (Ruiz-Villaverde and García-Rubio 2017; Papadopoulos and Warin 2007). Despite this, and despite the involvement of stakeholders in water management-related decision making being something that is both required and frequently practised (WMO 2009; Huitema et al. 2009), no standardised means for facilitating stakeholder participation exists. Nonetheless, numerous examples of failed or poorly implemented stakeholder participation can be seen across the literature (Reed 2008). Stakeholder participation may fail, for instance, if stakeholders are left subjectively unheard, leading to feelings of resistance and conflict; if they are involved at too late a stage in the decisionmaking process; or if the temporal demands placed upon them are such that they are unable to commit themselves to the process (Hommes et al. 2009; Reed 2008; Pahl-Wostl 2002; Andersson et al. 2008).

Stakeholder participation is considered especially important in situations with complex, unstructured problems - described previously as 'wicked' problems (Rittel and Webber 1973) ('messy' Ackhoff 1974 or 'ill-structured' problems Dunn 1988). Wicked problems often lack a straightforward answer because of incomplete, contradictory, or dynamic components that are often difficult to address directly (Brunner et al. 2005). They are characterised by ambiguity regarding problem definition, uncertainty involving the causality of relationships between problems and potential solutions, and disagreement surrounding important normative elements (e.g. values, norms or objectives) (Hisschemöller and Hoppe 1995). Many water management problems are 'wicked' because they comprise complex human and natural systems (Kolkman et al. 2005) often involving different governmental spheres (OECD 2011) and multiple stakeholders using the water system (Geldof 2001). Typical examples are problems relating to pharmaceuticals in the water system (KasprzykHordern et al. 2008), land subsidence as a result of groundwater extractions (Van den Born et al. 2016), and pluvial flooding during heavy rainfall (Farrelly and Brown 2011).

Given the (wicked) nature of these problems, the challenge for participatory methods lies in being able to interweave process-related elements with situation-specific content, thereby developing a shared understanding between stakeholders regarding the problem at hand (Edelenbos et al. 2003; Koppenjan and Klijn 2004). It has been argued that participatory methods can, and should, actively stimulate participant's understanding of one another's values and interests - as opposed to being solely directed towards consensus finding (Karpowitz and Mansbridge 2005). Stakeholders are thereby better able to recognise the moral merit of perspectives that are different from their own (Gutmann and Thompson 2009).

$\overline{{ }^{1} \text { http://ec.europa.eu/environment/aarhus }}$ 
Despite this growing recognition that an exploration of differing values, as well as interests, can be of significance to the deliberative process, and that participatory methods can be highly useful in recognising the (moral) merit of other people's perspectives, little attention has been given to methods that systematically address stakeholders' values, or their differing interpretation of these values. Empirical research from the energy sector suggests that moral and social values have a large impact on the general societal acceptance of energy projects (Gross 2007; Wustenhagen et al. 2007). A growing number of scholars are therefore calling for more comprehensive integration of moral values throughout the design of energy projects (Kostyk and Herkert 2012; Demski et al. 2015). Although less systematically studied, empirical evidence from the water domain suggests a similar positive effect in adopting a value-based approach over an interest-based one (Briggs et al. 2005; Glenna 2010; Doorn 2016).

'Values' are used in this article as the basis for describing stakeholder participation. This approach develops on that of Cheng and Fleischmann (2010) in treating values as underlying determinants of what people think is important in life. The concept of values is used to form a basis for the deliberation process - defined here as a group-based process of participation, social exchange, reflection, and learning - in which participants have the opportunity to reflect upon, form, express, and debate their viewpoints, values and beliefs (Kenter et al. 2016a). We focus on value deliberation in the early stage of the decision-making process in which direct stakeholders discuss possible solutions in order to ascertain existing and prevailing attitudes and values surrounding the problem in question. This is with the aim of understanding the role that value identification and discussion can play in this early stages of environmental decision-making, building on the ideas of Karpowitz and Mansbridge (2005), Gutmann and Thompson (2009), Doorn (2009), and Glenna (2010).

This article is structured as follows: Section 2 details the objectives of the research and the propositions to be tested. In Section 3, value elicitation, participatory deliberation, and the process of data collection are discussed. Next, Section 4 describes the results of the data collection at, respectively, a Dutch water research institute and a Dutch water board - allowing for analysis of the propositions. Following this is a discussion of the results in Section 5 and a section detailing related work. Finally, in Section 7 we present our conclusions and introduce possibilities for future research.

\section{Objectives}

Our aim is to use value deliberation to achieve stakeholder mutual understanding that will ultimately lead to better-supported water governance. This is achieved by integrating the values of the stakeholders involved in the process. Stakeholders can include policymakers, concerned citizens and business owners. Values that appear to be relevant to stakeholders should be expressed consistently over the course of the process (Gregory et al. 2005) to allow for good water governance. We aim to answer the following research question:

To what extent can the discussion of values impact the deliberation process concerning water governance issues?

In order to answer this question, we analyse two propositions constructed to define the extent of the impact of value discussions. First, we want to know whether the discussion of values affects the ranking order of alternative values. This leads to our first proposition:

P1: Making values part of the deliberation process may change participant's preferences with respect to the alternatives. 
This proposition is analysed by comparing participant's ranking of prefered values at the beginning of the deliberation to a ranking performed towards the end of the deliberation. In Section 3.2 this is explained further.

Second, whether a participant changes their preferences does not infer that their understanding of the preferences has changed. Increased understanding could lead to a change in preference ranking, or equally result in confirmation of the earlier ranked order of preferences (Barabas 2004). In order to test for a post-deliberation impact other than change in individual preferences, we investigate whether there is a change in participant understanding of other people's perspectives:

P2: The discussion of values during the deliberation process leads to an increased understanding of other perspectives.

We use the term 'understanding' here to describe an acquired acceptance of another viewpoint with a certain degree of sympathy, not the act of cognitive understanding. Proposition 2 is analysed through a post-workshop evaluation completed by participants, including a short survey.

\section{Methodology}

There has been ample research into methods that increase participation in social learning (Hommes et al. 2009; Pahl-Wostl 2002; Reed 2008; Cuppen 2012a; Renn et al. 1997), yet specific methods concerning value deliberation are scarce.

\subsection{Value Elicitation}

The main rationale for deliberating values instead of discussing interests is that value discussions have been shown to be able to transcend the inevitable interest-based disagreements amongst stakeholders (Glenna 2010; Doorn 2016), and instead become a dialogue around other people's perspectives. If participants understand each other's viewpoints and perceptions, they can be more willing to work towards a common solution (Habermas 1995). To reach this mutual understanding, participants have to be willing to reflect on their values, assumptions and larger social context. In addition, they must try to understand arguments from other perspectives through respectfully listening to each other (Dahlberg 2001).

Before one can investigate an appreciation or understanding of other people's values, the values themselves must first be identified. One potential approach to this is that researchers select the values they think are worthwhile investigating (Kenter et al. 2016b). 'Values' can be an abstract concept for participants, so having researchers preselect a defined set of values can make the concept clearer and more practical. The clear downside is that this makes the deliberation biased towards values chosen by the researchers.

Another approach, therefore, is to give participants total autonomy to identify which values they think are relevant. This could be facilitated either by imposing a definition of value, or by leaving it up to participants to dictate what they consider to be a value.

\subsection{Participatory Deliberation}

We took inspiration from the Delphi methodology, a much used and investigated datagathering method designed to elicit consensus amongst experts. This method is further able to determine a range of alternatives around a given discussion topic, and can also be used 
to delineate the underlying assumptions they are based on (Hsu and Sandford 2007). The Delphi method provides measurable outcomes and a clear structure: questionnaires are sent to preselected experts, their responses are summarised, and summaries are sent back to the experts together along with a second questionnaire comprising roughly the same questions. This is commonly done through completing two rounds of the process, but more can be performed if required. In the last round, the experts often rank the ideas generated in the questionnaires (Landeta 2006; Van de Ven and Delbecq 1974).

Using the iterative structure of the Delphi method, we organised two workshops based around two discrete (wicked) water governance problems. Each workshop contained participants with differing levels of expertise. The process is depicted in Fig. 1. Data were collected via rankings, group evaluation and a survey.

The deliberation starts with a formulation of alternatives that could solve the problem. Some of the alternatives may be pre-determined because they are 'standard' or currently investigated approaches to the problem. Additional or new alternatives can be introduced (Renn et al. 1993). For each alternative, pro and con arguments are collected.

Participants then rank all alternatives on a ranking form - from most preferable, ranked number one, to least preferable, ranked bottom - to establish a baseline preference measurement. Using the Borda count for the aggregation of individual rankings, any changes in personal ranking preferences can be tracked whilst remaining anonymous, ensuring that the outcome is unbiased towards individual voters (Young 1988).

The rankings are collected to calculate the aggregated score for each alternative. The alternative that scores highest on the aggregate level is not necessarily the most preferred alternative for participants individually. Therefore the individual rankings are considered as well, to have a complete overview of the changes in ranking behaviour. This information is used to analyse Proposition 1.

Values are then identified by asking participants what values they think are relevant per alternative, and if they can identify overarching values common across alternatives. The participants then reflect on why these values are important to them. Sharing these reflections forms the core of the deliberation (McCrum et al. 2009). Alternatives are then ranked again, after which point the differences between the two rankings (or a lack thereof) becomes visible and is discussed. These outcomes are used to analyse proposition 2. Furthermore, participants are asked if the process gave them any additional insights or taught them anything new by way of a short survey. The answers to this are used as a second unit of analysis for proposition 2 .

\subsection{Data Collection}

Data collection took place in the spring of 2017 over two workshops. In workshop 1, four researchers facilitated and documented a value deliberation process at a Dutch water

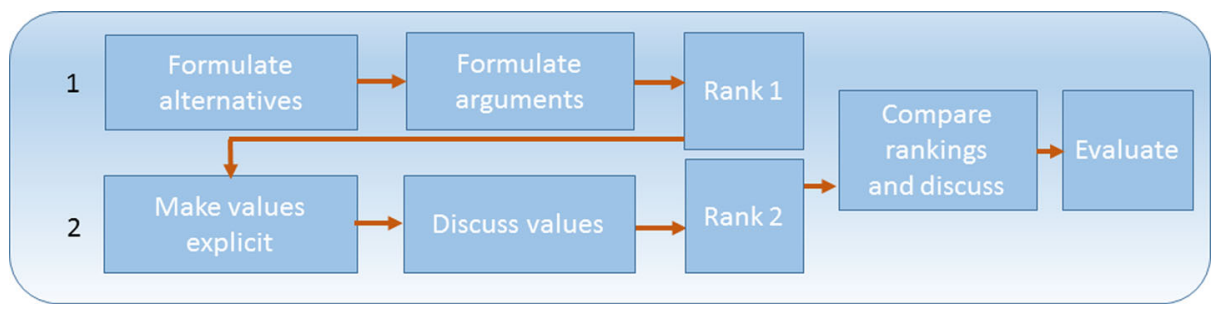

Fig. 1 Value deliberation process 
research institute. There were six participants, all connected to the water research institute, deliberating on the topic land subsidence.

In workshop 2, three researchers facilitated and documented a value deliberation process at the Dutch water board Waterschap de Dommel. Ten participants from the water board deliberated on the topic pharmaceuticals in the water system.

\section{Results}

In this section, we describe the results of the two workshops. In both workshops, participants contributed two additional alternatives to the list of pre-determined alternatives that served as a starting point.

\subsection{Workshop 1 on Land Subsidence}

For the measurement of impact and analysis of the propositions, the arguments are an aid rather than a key outcome. A complete overview of the arguments related to each alternative can be found in Appendix B, Table 1. The values that were identified are also listed in Table 1.

Rankings Aggregate rankings for the two rounds are depicted in Fig. 2.

The chart shows that, on aggregate, option $\mathrm{C}$ was ranked first, then option $\mathrm{B}$, and so on. The order of the aggregated preferences did not change in the second round (after the discussion).

The differences between the two rounds appear minor on an aggregate level, yet all participants changed their order of preferences in the second round, and one changed their most preferred alternative (see Appendix B).

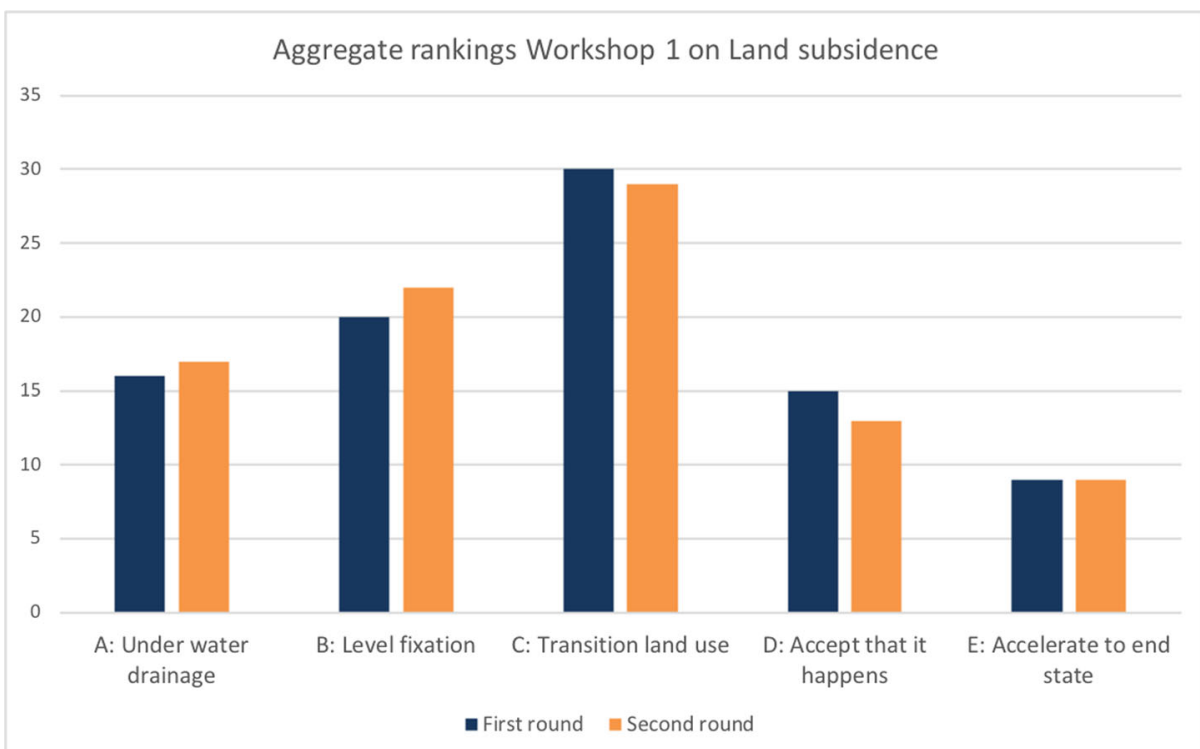

Fig. 2 Aggregate rankings of Workshop 1 
Group Evaluation During the evaluation, all participants explained why they had changed their order of preferences. Reasons given include that 'the urgency of the problem became clearer because of the value discussion' and 'too-invasive changes/alternatives became less important because of the discussion'. In summary, participants stated that the value discussion resulted in a better understanding of the problem and of the alternatives.

Discussion The discussion on values, guided by the questions 'What values did you write down?', 'Why?', 'Does everyone agree?', and 'Why not?', led to discussion of the values of cultural history, governance, safety, landscape innovation and landscape disappearance.

Survey In the survey (see Appendix A) participants were asked if their ideas had changed after the value discussion. Some of the responses given to this included: 'Yes, I have more understanding of the alternative and the impact of the alternative', and 'My ideas have become richer, more complete'. Another question asked was if the process taught them something new, or allowed for different insights to be gained. Participants responded, 'Not something new, but new points of view [from which] to approach the problem'; 'Maybe not content-wise, but it sharpens the mind'; and 'Different types of values [became apparent], that did not cross my mind before but which are actually very important'. The answers to these questions show that participants generally experienced a change after the value discussion, allowing them to better understand others' - as well as their own - perspectives.

\subsection{Workshop 2 on Pharmaceuticals in the Water System}

For this workshop, the complete overview of alternatives, arguments and values per argument can be found in Appendix C, Table 2.

Rankings The aggregate rankings of this workshop are depicted in Fig. 3. This shows that in the first round option A was most preferred, followed by the alternatives C, D, B, F and

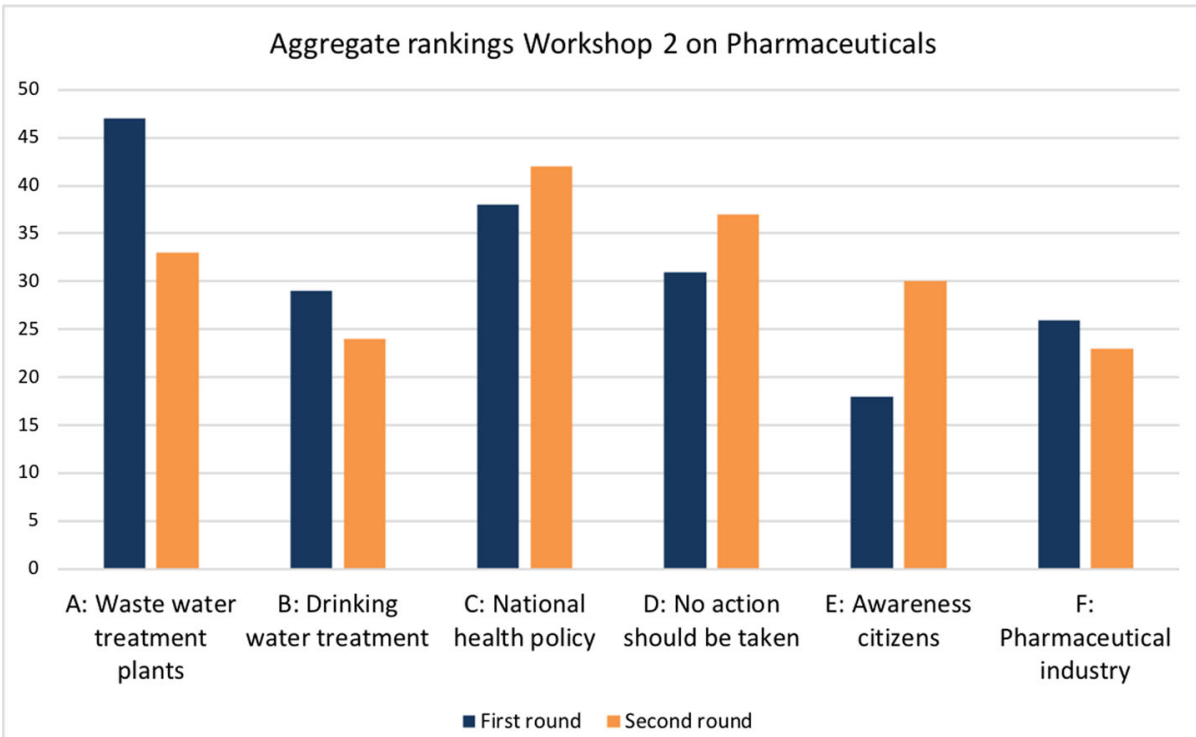

Fig. 3 Aggregate rankings for workshop 2 
E. However, the aggregated preferences changed after the second round, with $\mathrm{C}$ ranked first, followed by D, A, E, B and F.

One participant did not change anything, yet all others did. In addition, six of the nine participants changed their most preferred alternative in the second ranking (see Appendix C).

Group Evaluation During the evaluation, participants expressed their reasoning behind changing or maintaining their order of preferences, with explanations such as: 'In the first round I reflected from the water-authority perspective; in the second I reflected on the values for society'; 'First I thought: what is the most practical to do? But then I realised that we are really going the wrong way - something really needs to change'; and 'There is no wrong or right. It feels very good to discuss it in such way.'

Discussion The discussion on values expanded into a discussion concerning personal values, societal values and organisational values. Values that were discussed were the concept of 'Gaia' (the theory that sees the earth is a complex, living organism), priorities, survival, own responsibility, and safety. Participants told personal stories about the future of their children and the lives of their elderly parents to express what these values meant to them. This made the discussion per value longer than in workshop 1, and more personal. Participants stated that the realisation that these issues (around pharmaceuticals in the water system) had become personal was only apparent after the value discussion had occurred.

Survey To the question of whether participants' ideas had changed after the value discussion, answers included: 'No, but I could understand my thoughts after the discussion about values better', and 'Yes, [my ideas changed as a result of] thinking more about society's point of view'.

To the question of whether the deliberative process gave them different insights, participants' stated, 'Yes, [in] making explicit that people have values and discussing them', and 'More understanding of differences [allowed for] insights in the complexity of the issue'.

Most participants expressed that they had gained new insights because of the deliberation (five out of six in Workshop 1, and eight out of ten in Workshop 2).

\section{Discussion}

Our aim was to develop a better understanding of the role of value discussions in deliberative processes. In this section, we first reflect on the measurability of the deliberation process and on how values were identified and discussed. This is followed by a discussion of the propositions and research question.

\subsection{How We Measured Value Deliberation}

Deliberation took place in an environment conducive to open discussion; in which participants felt free to speak up and to reflect on their values. Measurements were performed using a ranking process whereby the preferences of participants are quantified and become easily comparable.

In workshop 1, the value discussion did not result in large changes in aggregate rankings. The discussion was vivid, but participants tended to express a similar set of moral 
convictions, or adopt a similar 'worldview'. This led to rankings that were fairly homogenous. All participants, however, changed their rankings between first and second rounds.

The aggregate rankings from Workshop 2, however, exhibited substantial differences. Even though all participants were working for the water authority, they displayed highly different ideas regarding the discussed values. The value 'Gaia' drew particularly intense discussion, developing into an exchange of personal stories to support each participant's values. This discussion resulted in changes in the rankings on an aggregated level.

In both workshops, new alternatives were suggested and brought to the table, allowing the discussion to adopt a more comprehensive view of the topics. The participants became aware of their own conceptions of values and of those of other participants. Stories regarding values became both factually rooted and highly personal, and allowed participants to understand each other better. In the evaluative discussions for both workshops, participants stated that they had obtained a better understanding of the problem, the alternatives, and what is at stake with respect to the values relevant to all stakeholders.

Identifying values was not a goal in itself, but rather an instrument to support a deliberative process that invites participants to reflect on the topic in more abstract terms. The aim was to transcend discussion on the level of interests, which was achieved.

The moderator did not set rules detailing what constitutes a value and what does not. Not being strict regarding this definition created room for an open-ended identification of values. This resulted in values that could be actual sentences (e.g. 'We are a societal player, so we are part of the issue'), worries (e.g. bad for economy), or opposing concepts presented under one label (e.g. landscape innovation and landscape disappearance).

In both workshops, many different values were identified by participants (an overview of the values can be found in Tables 1 and 2 in the Appendices) and the value elicitation evolved organically; there was a sense of openness in which no input was considered 'wrong'.

During the Workshop 2 discussion on pharmaceuticals in the water system, participants described that their perspective on the topic seemed to have shifted to a personal one, even though all participants were present in the role of water authority representatives. If value discussion can allow participants to temporarily relax or step aside from their official role - simply by virtue of becoming focused or engaged in the topic under discussion - this could create a way of approaching the complex social process whereby stakeholders have to meet in often less harmonious settings. It could open up new discussions and challenges between stakeholders; ones that were not conceivable before. This is reflected in the previously posited idea that diversity - and open-mindedness in perspectives and opinions - can be considered a prerequisite for proper deliberation in which participants learn from each other and reflect on each other's perspectives (Barabas 2004; Cuppen 2012b). In addition, opening up on a personal level during the workshop can facilitate increased feelings of trust amongst participants (Kenter et al. 2016a).

In Workshop 2, the differences between the individual rankings increased in the second round. This scenario could be seen as expected, as earlier research has described how deliberation can bring pre-existing differences to the surface, diverging the perspectives of participants rather than converging them (Shapiro 2002). If participants' expectations are well facilitated during the deliberation, such divergence is not necessarily a problem; deliberation in an early stage is meant to allow participants to understand each other better and to develop an awareness of the different concepts present.

Through conducting two separate, small-scale studies - in which external researchers assume the role of facilitators - group dynamics could be observed and interactions could 
be documented. The experimental, qualitative, and small-scale nature of this study does not allow for statistical analysis. However, if the same methodology were performed on a larger scale, the rank orders obtained through the Borda count allow for calculation of KemenySnell distance (Kemeny and Snell 1972) to evaluate whether the rankings of a deliberation have become more similar in a second measurement.

\subsection{Proposition Testing and Answering Research Question}

We analysed two propositions to answer our research question. The first proposition was evidenced in Workshop 1 whereby all participants changed their preferences. In Workshop 2 , the changes in preferences were even more apparent: six of the nine participants changed their most preferred alternative after the value discussion. These results confirm that making values explicit and subject to group discussion can change a participant's preference of the alternatives.

The second proposition was confirmed in both workshops. In Workshop 1, the group evaluation reported a clarification of the problem and the alternatives; the survey, in turn, reported a broadening in understanding. One participant described specifically an increased understanding of other perspectives: 'I appreciated the change-over between the technologies and the values. Hearing values from others has an effect that your own scope is broadened; you get empathy for others. For example, if you hear others talk about the speed of the transition, this gives new insights that adjust your own understanding and opinion. You cannot attack someone on their values. Hearing the values of another participant influences your own opinion.'

In Workshop 2, one of the reasons that the understanding of participants had changed was that that they were able to reflect on the values from differing perspectives: their professional perspective as a representative of the water board; a societal perspective; and as a private citizen, reflecting on the personal consequences that the issue encompasses. In particular, the differing views and discussion arising with respect to the value 'Gaia' reflected thoughts that were not expressed before by the participants.

This leaves us to finally to consider our original research question: To what extent can the discussion of values impact the deliberation process concerning water governance issues? Based on the analysis of the two workshops we can see that deliberation of values changes both participants' preferences and increases the understanding of other perspectives. This finding is a promising first step to improve the deliberation and subsequently decisionmaking processes in water governance.

\section{Related Work}

Research based both in environmental governance and innovative democracy has yielded studies describing the significance of deliberation. In a study on methods of enhancing social learning, researchers organised deliberative workshops allowing land managers to share and deliberate their reflections on climate change (McCrum et al. 2009). These workshops stimulated social learning, but neither mutual understanding nor values were taken into account. Kenter et al. (2016b) discuss how to combine value deliberation with groupbased decision-making in managing ecosystems. The goal of these studies was to deliberate on monetary values through various workshops in which information is elicited and values become explicit. No deliberation took place, however, concerning stakeholders' moral values. 
Deliberative democracy is a process by which to involve citizens in decision-making processes for policies (Mouffe 1999; Gastil and Levine 2005; Gutmann and Thompson 2009). The role of values in these deliberations is only mentioned sparsely, but - when discussed - is presented as a crucial aspect (Karpowitz and Mansbridge 2005). Nonetheless, no systematic attempts to realise this are discussed in the deliberative democracy literature.

Additionally, the concept of perspective-taking in relation to decision-making is investigated within the field of social psychology (Galinsky et al. 2014). The study discusses how perspective-taking is able to influence decision-makers, and seems to prevent them from clashing with others in the process. However, the results are laboratory-based, with students role-playing the decision-making process. In addition, the experiments did not focus on moral values.

\section{Conclusions and Further Research}

Numerous examples of issues of water governance can be characterised as wicked problems, with corresponding difficulties in stakeholder participation. The goal of this study was to increase participants' understanding of other participants' perspectives - through discussing values instead of interests. We explored the role of value discussions as part of stakeholder participation for water governance by facilitating two workshops. The first workshop was a deliberation on land subsidence; the second concerned pharmaceuticals in the water system. In both workshops we facilitated the identification of relevant values. This resulted in a rich palette of values that were reflected upon through vivid discussions. For all participants, deliberating on values was a new way of reflecting on the topic. Most participants stated that their understanding of both the topic and of perspectives other than their own had increased.

The two workshops validated Proposition 1: that value deliberation changes a participant's preferences. In Workshop 1, all participants changed their rankings; in Workshop 2, all but one participant changed their ranking.

Proposition 2 - that value deliberation leads to an increased understanding of other perspectives - was confirmed in both workshops, making value deliberation a promising approach to incorporate into policy-making processes in general, and water governance policies in particular.

One of the limitations in this research is the lack of diversity in stakeholders, as all participants in both workshops were colleagues. In future research, the group of participants should represent the diversity of stakeholders inherent in such wicked problems. We expect this to affect the dynamics during the workshop. A new proposition could be to test whether a greater diversity in perspectives among participants increases the impact of the deliberation.

A challenge in deliberating with more diverse stakeholders is that trust among the participants is not implicit and pre-existing, yet it is necessary that they work collaboratively towards a shared goal (Focht and Trachtenberg 2005). This does not mean that the participants should have similar ideas on a topic. However, it does require that there is an environment of mutual respect in which participants feel safe to share their ideas and perceptions, even though these may diverge or conflict (McDonough and Cedrone 2000).

Since this study was the first to measure the impact of value deliberation on water governance issues, we constructed a small-scale study using two cases. This scale provided enough room to collect participants' experiences in a qualitative way, which not only resulted in measuring the impact, but also lead to an understanding of why there was an impact. 
The intuitive next step of this study would be to scale-up in order to perform a statistical analysis on the impact of value discussions. The Borda count allows for statistical analysis when large amounts of deliberations are held, all using the same method and tools, and in the same context. A tool would need to be devised so that the data can be collected by multiple facilitators simultaneously and in a uniform way. This can be achieved by developing a data collection tool and by training facilitators in the use of the method and the tool. The number of people participating per workshop should remain within the current range - under ten or meaningful discussions in which all members of the group can participate would become difficult.

Acknowledgments We are grateful of the Water research institute and Waterschap de Dommel for organising the workshops and for the fruitful collaboration. Further, we thank the anonymous reviewers for their valuable comments.

This work is part of the Values4Water project, subsidised by the research programme Responsible Innovation, which is (partly) financed by the Netherlands Organisation for Scientific Research (NWO) under Grant Number 313-99-316. The work of Neelke Doorn is supported by NWO under Grant Number 016-144-071.

\section{Compliance with Ethical Standards}

\section{Conflict of interests None}

Open Access This article is distributed under the terms of the Creative Commons Attribution 4.0 International License (http://creativecommons.org/licenses/by/4.0/), which permits unrestricted use, distribution, and reproduction in any medium, provided you give appropriate credit to the original author(s) and the source, provide a link to the Creative Commons license, and indicate if changes were made.

\section{Appendix A: Survey}

The survey as distributed at the end of the workshops. Since both workshops were held in Dutch, the original survey was also composed in Dutch. This is the English translation.

\section{Process}

1. Can you describe what you think of the process?

2. Did you think the process was clear?

3. Did you think the process was useful?

4. Did your ideas change after discussing the values? Can you explain why (or why not)?

5. Did the process teach you something new? Give different insights?

\section{Role in the process}

6. What is your job title?

7. What is your experience with the topic on a scale from 1 to 7 , where 1 stands for no experience at all, and 7 for a lot of experience?

8. Do you have a direct stake in the final decision that will be made?

\section{Appendix B: Outcomes workshop 1}

Outcomes ranking per participant for workshop 1: ranking 1 - ranking 2 


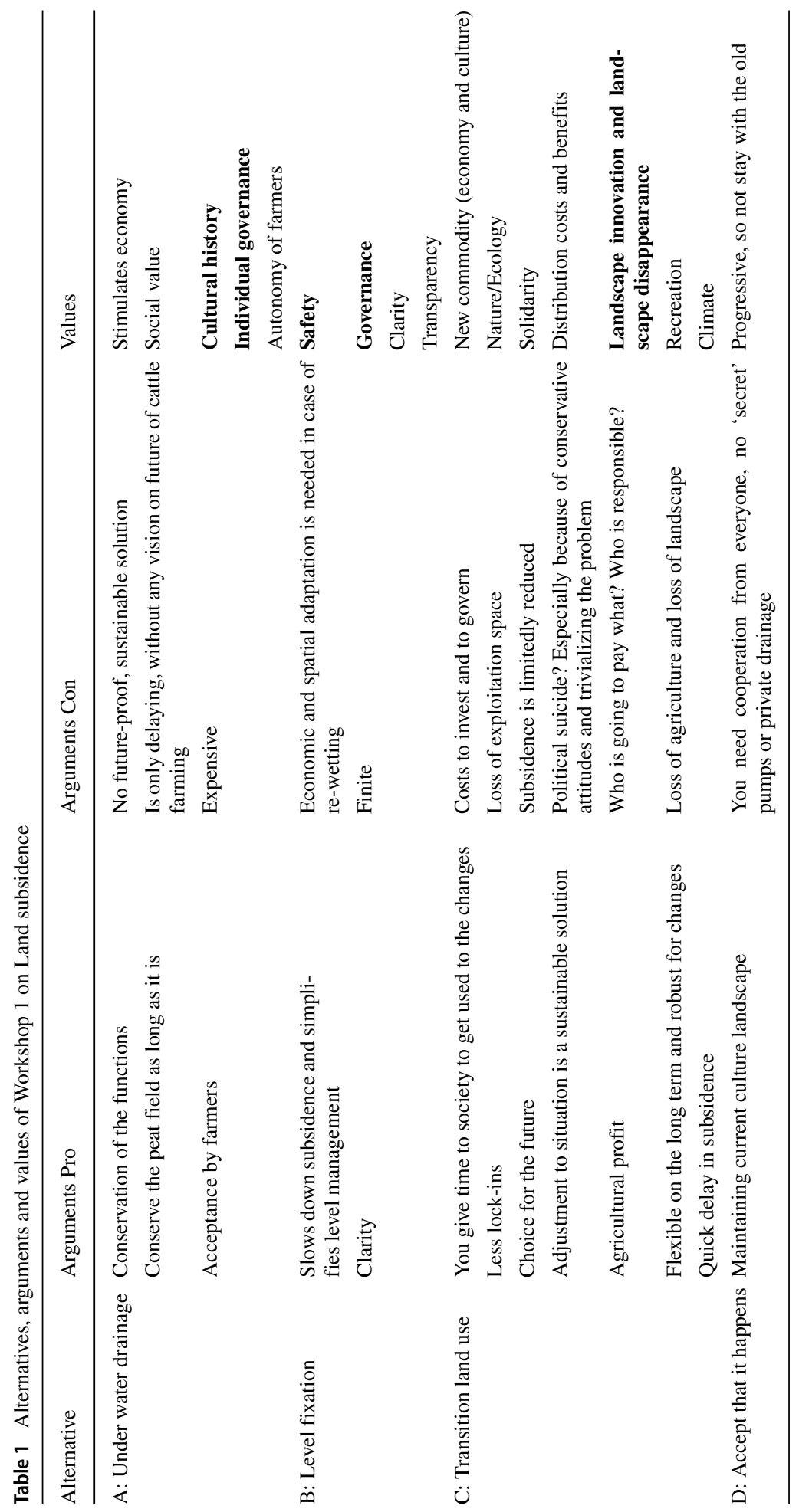




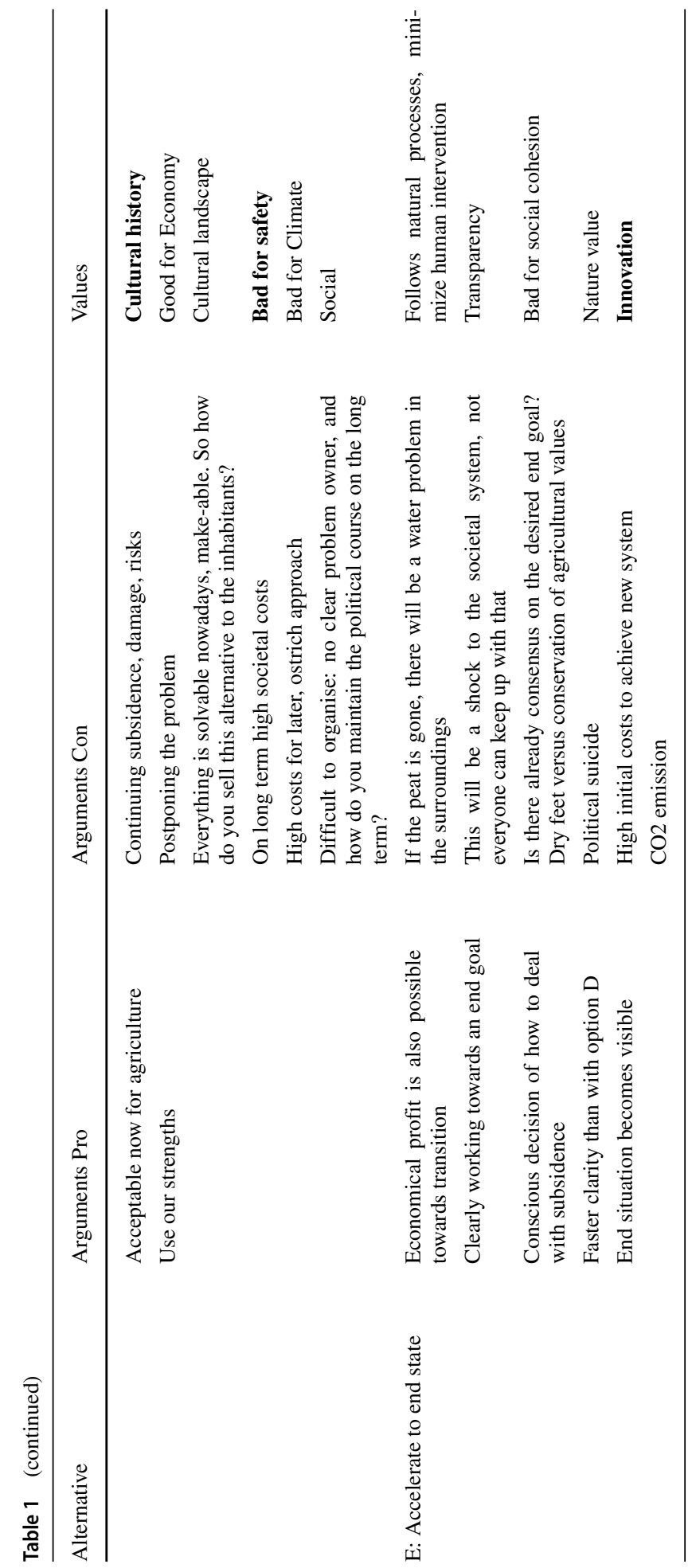


1. CDBAE - CBADE

2. CDBAE - CBADE

3. CDBAE - CDEAB

4. CABED - CBADE

5. CBAED - BCAED

6. CBAED - CBADE

The overview of alternatives, arguments and values of workshop 1 are listed in Table 1. Arguments and values are written down in a random order. The values that were discussed are marked in bold.

The values that were mentioned as overarching, not related to one specific alternative are: agriculture, economy, solidarity, safety, ease, democratic values, we are a knowledge economy, making money with agriculture is so last century, agricultural economics, local assignment, national assignment, intragenerational justice, intergenerational justice, future resistance, the pollutant pays.

\section{Appendix C: Outcomes of workshop 2}

Outcomes ranking per participant for workshop 2: ranking 1 - ranking 2

1. AFBECD - CEFABD

2. ACBDFE - CEDABF

3. DBFCEA - DCEFBA

4. ADCBFE - DACBFE

5. FCABED - FCABED

6. ADCBEF - DACFBE

7. ACDBEF - DCBAEF

8. ACFEDB - AEBCFD

9. $\mathrm{ACDBEF}-\mathrm{DECABF}$

The overview of alternatives, arguments and values of workshop 2 are listed in Table 2. Arguments and values are per alternative written down in a random order. Values that were discussed are marked in bold.

The values that were mentioned as overarching: a healthy society, future of clean and healthy environment, protect water for future generations, prevention is better than healing, awareness, sustainability, quality of life, survival. 


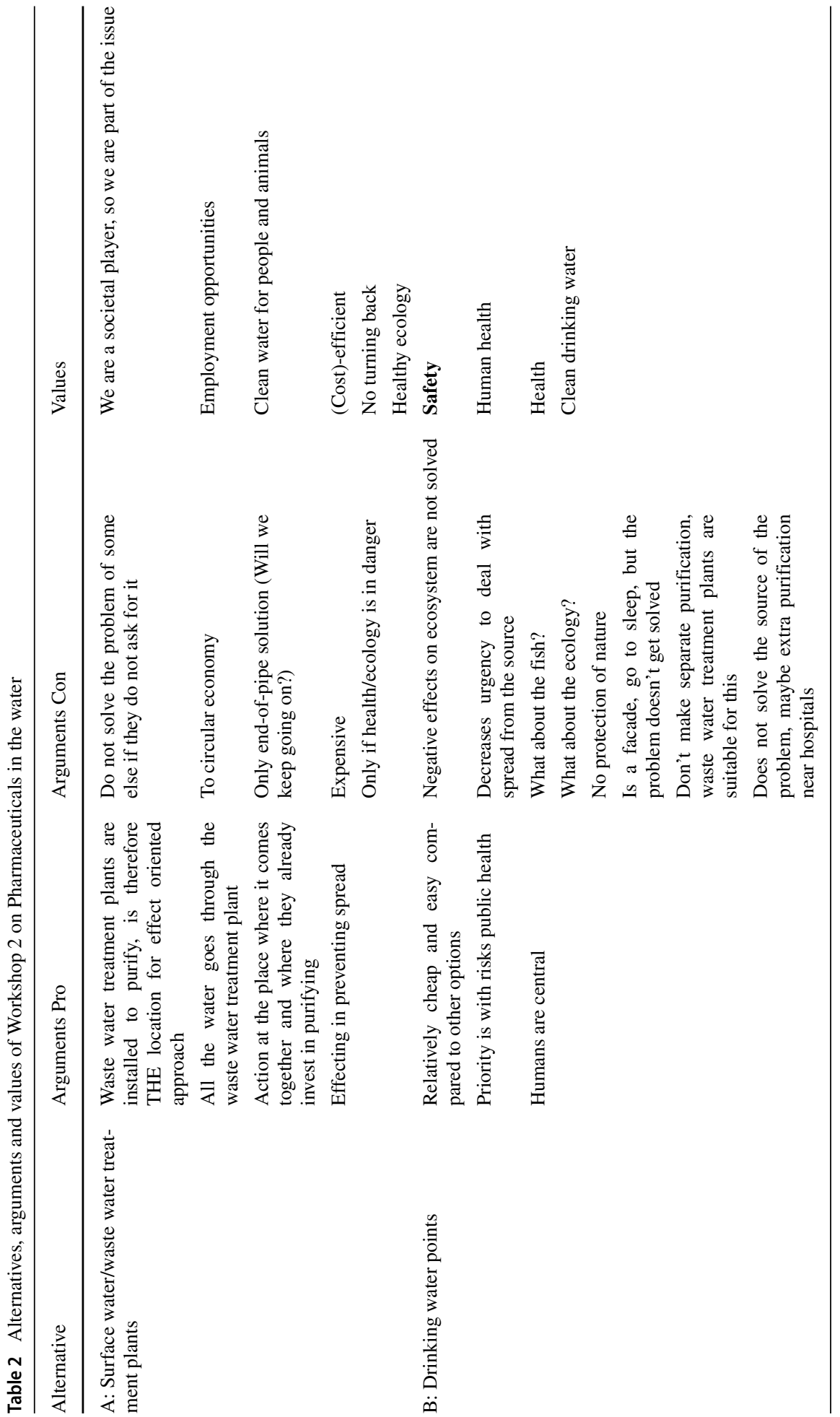




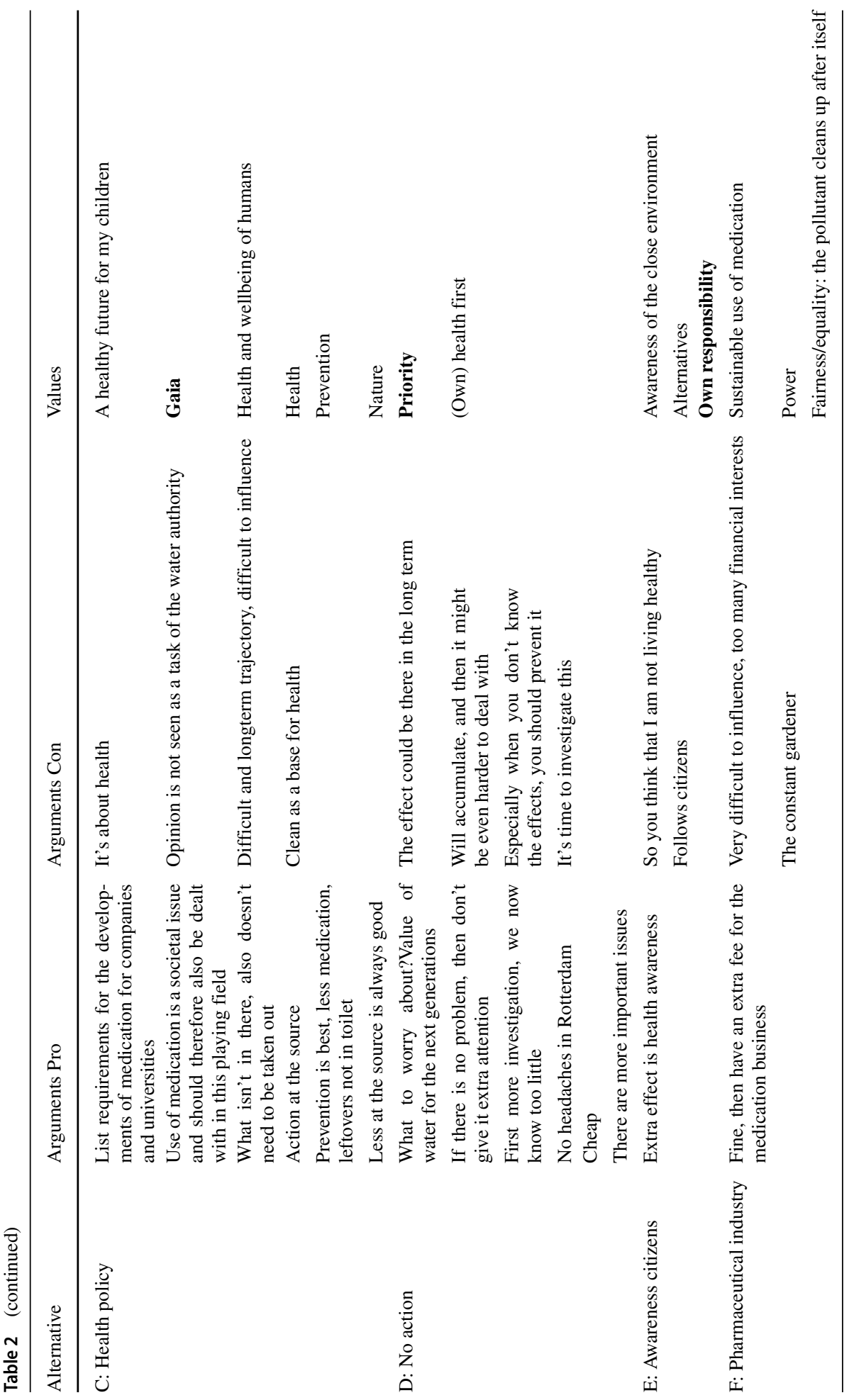




\section{References}

Ackhoff R (1974) Redesigning the future. Wiley, New York

Andersson L, Olsson JA, Arheimer B, Jonsson AC (2008) Use of participatory scenario modelling as platforms in stakeholder dialogues. Water SA 34(4):439-447

Barabas J (2004) How deliberation affects policy opinions. Am Polit Sci Rev 98(4):687-701

Briggs R, Kolfschoten G, De Vreede G-J (2005) Toward a theoretical model of consensus building. AMCIS 2005 Proceedings

Brunner RD, Steelman TA, Coe-Juell L, Cromley CM, Edwards CM, Tucker DW (2005) Adaptive governance: integrating science policy and decision-making. Columbia University Press, New York

Cheng A, Fleischmann K (2010) Developing a meta-inventory of human values. Proc Am Soc Inf Sci Technol 47(1):1-10

Cuppen E (2012a) Diversity and constructive conflict in stakeholder dialogue: considerations for design and methods. Policy Sci 45(1):23-46

Cuppen E (2012b) A quasi-experimental evaluation of learning in a stakeholder dialogue on bio-energy. Res Policy 41(3):624-637

Dahlberg L (2001) The internet and democratic discourse: exploring the prospects of online deliberative forums extending the public sphere. Inform Commun Soc 4(4):615-633

Demski C, Butler C, Parkhill KA, Spence A, Pidgeon NF (2015) Public values for energy system change. Glob Environ Chang 34:59-69

Doorn N (2009) Applying Rawlsian approaches to resolve ethical issues: inventory and setting of a research agenda. J Business Ethics 91:127-143

Doorn N (2016) Governance experiments in water management: from interests to building blocks. Sci Eng Ethics 22(3):755-774

Dunn W (1988) Methods of the second type: coping with the wilderness of conventional policy analysis. Polic Stud Rev 7(4):720-737

Edelenbos J, Monnikhof R, Van de Riet O (2003) A double helix approach: a proposal to forge a better integration of analysis and policy development. Int J Technol Polic Manag 3(1):1-21

Farrelly M, Brown RR (2011) Rethinking urban water management: experimentation as a way forward? Glob Environ Chang 21(2):721-732

Focht W, Trachtenberg Z (2005) A trust-based guide to stakeholder participation. In: Sabatier PA, Focht W, Lubell M, Trachtenberg Z, Vedlitz A, Matlock M. (eds) Swimming upstream: collaborative approaches to watershed management. MIT Press, Cambridge, pp 85-136

Galinsky AD, Magee JC, Rus D, Rothman NB, Todd AR (2014) Acceleration with steering: the synergistic benefits of combining power and perspective-taking. Soc Psychol Personal Sci 5(6):627-635

Gastil J, Levine P (eds) (2005) The deliberative democracy handbook: strategies for effective civic engagement in the twenty-first century. Jossey-Bass

Geldof G (2001) Omgaan met complexiteit bij integraal waterbeheer. University of Twente, PhD thesis

Glenna L (2010) Value-laden technocratic management and environmental conflicts: the case of the New York City watershed controversy. Sci Technol Human Values 35(1):81-112

Gregory R, Fischoff B, McDaniels T (2005) Acceptable input: using decision analysis to guide public policy deliberations. Decis Anal 2(1):4-16

Gross C (2007) Community perspectives of wind energy in australia: the application of a justice and community fairness framework to increase social acceptance. Energy Polic 35(5):2727-2736

Gutmann A, Thompson D (2009) Why deliberative democracy? Princeton University Press

Habermas J (1995) Reconciliation through the public use of reason: remarks on John Rawls's political liberalism. J Philos, 109-131

Hisschemöller M, Hoppe R (1995) Coping with intractable controversies: the case for problem structuring in policy design and analysis. Knowl Technol Polic 8(4):40-60

Hommes S, Vinke-de Kruijf J, Otter H, Bouma G (2009) Knowledge and perceptions in participatory policy processes: lessons from the delta-region in the netherlands. Water Resour Manag 23:1641-1663

Hsu C, Sandford B (2007) The Delphi technique: making sense of consensus. Pract Res Assess Eval 12:10

Huitema D, Mostert E, Egas W, Moellenkamp S, Pahl-Wostl C, Yalcin R (2009) Adaptive water governance: assessing the institutional prescriptions of adaptive (co-)management from a governance perspective and defining a research agenda. Ecol Soc 14:1

Karpowitz CF, Mansbridge J (2005) Disagreement and consensus: the need for dynamic updating in public deliberation. J Public Delib 1:1

Kasprzyk-Hordern B, Dinsdale R, Guwy A (2008) The occurrence of pharmaceuticals, personal care products, endocrine disruptors and illicit drugs in surface water in South Wales, UK. Water Res 42(13):3498-3518 
Kemeny J, Snell J (1972) Mathematical models in the social sciences, chapter II preference ranking: an axiomatic approach. MIT Press, pp 9-23

Kenter J, Reed M, Fazey I (2016a) The deliberative value formation model. Ecosyst Serv 21:194-207

Kenter JO, Jobstvogt N, Watson V, Irvine K, Christie M, Bryce R (2016b) The impact of information, valuedeliberation and group-based decision-making on values for ecosystem services: integrating deliberative monetary valuation and storytelling. Ecosyst Servi 21:270-290

Kolkman M, Kok M, van der Veen A (2005) Mental model mapping as a new tool to analyse the use of information in decision-making in integrated water management. Phys Chem Earth 30:317-332

Koppenjan JFM, Klijn E (2004) Managing uncertainties in networks: a network approach to problem solving and decision making. Routledge, London

Kostyk T, Herkert J (2012) Societal implications of the emerging smart grid. Commun ACM 55(11):34-36

Landeta J (2006) Current validity of the Delphi method in social sciences. Technol Forecast Social Change 73(5):467-482

McCrum G, Blackstock K, Matthews K, Rivington M, Miller D, Buchan K (2009) Adapting to climate change in land management: the role of deliberative workshops in enhancing social learning. Environ Polic Governance 19(6):413-426

McDonough EF III, Cedrone D (2000) Managers at work: meeting the challenge of global team management. Res-Technol Manag 43(4):12-17

Mostert E (2003) The challenge of public participation. Water Polic 5(2):179-197

Mouffe C (1999) Deliberative democracy or agonistic pluralism? Social Res 66(3):745-758

OECD (2011) Water governance in OECD countries: a multi-level approach. OECD Publishing

Pahl-Wostl C (2002) Partcipative and stakeholder-based policy design, evaluation and modeling processes. Integrated Assess 3(1):3-14

Papadopoulos Y, Warin P (2007) Are innovative, participatory and deliberative procedures in policy making democratic and effective? Europ J Polit Res 46(4):445-472

Reed M (2008) Stakeholder participation for environmental management: a literature review. Biolog Conserv 141:2417-2431

Renn O, Blättel-Mink B, Kastenholz H (1997) Discursive methods in environmental decision making. Bus Strateg Environ 6(4):218-231

Renn O, Webler T, Rakel H, Dienel P, Johnson B (1993) Public participation in decision making: a three-step procedure. Polic Sci 26(3): 189-214

Rittel H, Webber M (1973) Dilemmas in a general theory of planning. Polic Sci 4(2):155-169

Ruiz-Villaverde A, García-Rubio M (2017) Public participation in european water management: from theory to practice. Water Resour Manag 31(8):2479-2495

Shapiro I (2002) Optimal deliberation? J Polit Philos 10(2):196-211

Van Asselt M, Rijkens-Klomp N (2002) A look in the mirror: reflection on participation in integrated assessment from a methodological perspective. Global Environ Change 12(3):167-184

Van de Ven AH, Delbecq AL (1974) The effectiveness of nominal, Delphi, and interacting group decision making processes. Acad Manag J 17(4):605-621

Van den Born G, Kragt F, Henkens D, Rijken B, van Bemmel B, van der Sluis S (2016) Dalende bodems stijgende kosten. Technical report, PBL Netherlands Environmental Assessment agency

WMO (2009) Integrated flood management. Concept paper. World Meteorological Organization

Wustenhagen R, Wolsink M, Burer MJ (2007) Social acceptance of renewable energy innovation: an introduction to the concept. Energy Polic 35(5):2683-2691

Young HP (1988) Condorcet's theory of voting. Am Polit Sci Rev 82(4):1231-1244

Publisher's Note Springer Nature remains neutral with regard to jurisdictional claims in published maps and institutional affiliations. 